\title{
Uji Efektifitas Dinding Ruangan Panoramik Instalasi Radiologi RSUD Prof. Dr. MA Hanafiah SM Batusangkar Menggunakan TLD-100
}

\author{
D. N. Dasril ${ }^{*}$, N. Dewilza \\ Program Studi DIII Radiologi, Universitas Baiturrahmah, Indonesia \\ *Email: dilanelvodasril@atro.unbrah.ac.id
}

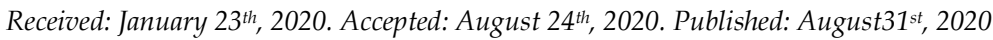

\begin{abstract}
Abstrak
Telah dilakukan penelitian tentang uji efektifitas dinding ruangan panoramik di Instalasi Radiologi RSUD Prof. Dr. MA Hanafiah SM Batusangkar. Penelitian ini bertujuan untuk mengetahui efektifitas dinding ruang panoramik dalam menyerap radiasi yang dikeluarkan oleh pesawat panoramik, serta mengetahui tingkat keamanan ruangan di sekitar ruang pemeriksaan panoramik sesuai dengan nilai batas dosis pekerja dan masyarakat umum. Jenis penelitian ini merupakan penelitian kuantitatif dengan melakukan pengukuran secara langsung. Penelitian dilakukan dengan cara pengukuran dosis radiasi pada enam titik dinding ruangan panoramik menggunakan alat ukur radiasi yaitu TLD-100. Hasil penelitian menunjukkan bahwa efektifitas dinding hanya mampu menyerap radiasi kurang dari $90 \%$, dengan kategori perisai pada dinding yang kurang baik dalam menahan radiasi. Oleh karena itu, diperlukan renovasi dinding ruangan panoramik yang sesuai dengan standar keamanan.
\end{abstract}

\begin{abstract}
Research on the effectiveness of panoramic room walls has been carried out in the Radiology Installation of Prof. Dr. MA Hanafiah SM Batusangkar. This study aims to determine the effectiveness of the panoramic room walls in absorbing radiation emitted by panoramic aircraft, as well as knowing the safety level of the room around the panoramic inspection room in accordance with the dose limit values of workers and the
\end{abstract}


general public. This type of research is a quantitative research by taking direct measurements. The research was conducted by measuring the radiation dose at six points of the panoramic room wall using a radiation measuring instrument, namely TLD-100. The results showed that the effectiveness of the walls was only able to absorb radiation less than $90 \%$, with the shield category on the walls that was not good enough to withstand radiation. Therefore, it is necessary to renovate the panoramic room walls in accordance with safety standards. C2020PERJ

Keywords: Radiation exposure rate ; TLD-100; shielding effectiveness of radiation.

\section{PENDAHULUAN}

Radiologi merupakan ilmu cabang kedokteran yang betujuan melihat bagian tubuh manusia dengan menggunakan pancaran atau radiasi gelombang. Radiologi dibagi menjadi dua, yaitu radioagnostik dan radioterapi. Penempatan rumah sakit di suatu daerah yang sudah diusahakan sestrategis mungkin dengan pemukiman penduduk daerah tersebut harus juga diimbangi dengan perhatian khusus terhadap aspek keselamatan masyarakat sekitar (Trikasjono et al., 2015). Berdasarkan Peraturan Kepala BAPETEN Nomor 8 Tahun 2011 tentang Keselamatan Radiasi dalam Penggunaan Pesawat Sinar- $X$ Radiologi Diagnostik dan Intervensional, rumah sakit yang menyediakan pemeriksaan menggunakan pesawat sinar- $X$ harus memperhitungkan denah ruangan yang meliputi ukuran, bahan, dan ketebalan dinding ruangan (Bapeten, 2011).
Pelayanan kesehatan kepada masyarakat di zaman sekarang berkembang sangat pesat, khususnya pelayanan di bidang radiologi; misalnya pemeriksaan panoramik. Panoramik merupakan salah satu foto rontgen ekstraoral yang telah digunakan secara umum di dunia kedokteran gigi untuk mendapatkan gambaran utuh dari keseluruhan rahang (Menteri Kesehatan Republik Indonesia, 2008).

Penegakan diagnosa suatu penyakit sangat bergantung pada berbagai peralatan penunjang. Fasilitas tersebut harus digunakan secara efektif untuk memberikan pelayanan kesehatan dengan mutu yang terjamin, dan tingkat keakurasian serta keamanan yang dapat diandalkan (Martem et al., 2015). Salah satu sumber radiasi adalah sinar- $X$ yang diproses menjadi sebuah gambaran radiografi. Sinar- $X$ termasuk jenis radiasi pengion yang mempunyai potensi bahaya lebih besar dari jenis radiasi lainnya (Hiswara, 2015). 
Panoramic disebut juga orthopamomografi atau rotografi (Street, 1994). Secara etimologis, orthopamomografi berasal dari kata:

1. Ortho, berasal dari bahasa Yunani yang berarti normal atau lurus.

2. Pan, berasal dari bahasa Inggris yang berarti menyeluruh.

3. Tomos, berasal dari bahasa Yunani yang berarti potongan atau irisan.

4. Graphic, berasal dari bahasa Yunani yang berarti gambaran atau catatan.

Berdasarkan asal kata tersebut dapat disimpulkan bahwa orthopamomografi (OPG) berarti pemeriksaan radiologi dari gigi beserta rahangnya yang berbentuk melengkung sehingga terlihat gambaran yang lurus dari film dengan menggunakan prinsip tomografi (Ancila \& Hidayanto, 2016).

Pengelolaan yang hati-hati terhadap sumber sinar- $X$ dengan melakukan proteksi radiasi baik terhadap pasien, petugas rumah sakit, maupun petugas radiologi akan menghasilkan keamanan dan keselamatan radiasi di sekitar ruangan radiologi (White \& Mallya, 2012). Tujuan keselamatan radiasi adalah untuk memberikan perlindungan terhadap kemungkinan akibat negatif dari pemanfaatan radiasi pengion (Dianasari, 2016)
Dosimetri merupakan ilmu atau teknik yang mempelajari besaran dan satuan radiasi, sedangkan dosis adalah adalah kuantisasi dari proses yang ditinjau sebagai akibat radiasi mengenai materi (Hiswara, 2015). Besaran yang digunakan dalam dositometri adalah :

1. Paparan atau exposure adalah besaran radiasi yang pertama kali diperkenalkan pada tahun 1928 ketika kongres radiologi sebagai kemampuan sinar $X$ atau foton gamma untuk menimbulkan ionisasi pada udara. 1 Rontgen ( $1 \quad \mathrm{R})$ didefinisikan sebagai besarnya penyinaran yang dapat menyebabkan terbentuknya muatan listrik sebesar 1 esu (electro static unit) pada elemen volume sebesar 1 cc pada kondisi temperatur dan tekanan normal. Secara matematis, rumus paparan ditunjukkan pada Persamaan 1.

$$
X=\frac{d Q}{d m}
$$

2. Dosis serap adalah energi ratarata yang diserap bahan persatuan masa. Radiasi dapat mengakibatkan ionisasi pada jaringan. Dosis serap tidak tergantung pada jenis radiasi, energi radiasi, dan sifat bahan penyerap, tetapi tergantung pada jumlah energi radiasi yang diserap per satuan massa dan bahan yang menerima penyinaran radiasi tersebut. Rumus dosis serap ditunjukkan pada Persamaan 2. 


$$
D=\frac{d E}{d m}
$$

3. Dosis ekivalen adalah besaran dositometri yang berhubungan langsung dengan efek biologi. Pada prinsipnya, dosis ekivalen adalah dosis serap yang telah dikalikan dengan faktor bobotnya; sesuai yang ditunjukkan pada Persamaan 3.

$$
H_{T R}=W_{R} \cdot D_{T R}
$$

Keterangan:

$H_{T R}=$ Dosis ekivalen

$W_{R}=$ Faktor bobot radiasi, dengan nilai faktor bobot radiasi untuk sinar- $X$ adalah 1

$D_{T R}=$ Dosis serap

Laju dosis radiasi elektromagnetik berbanding lurus dengan intensitas radiasi, maka nilai efektifitas dinding ruangan pemeriksaan dapat dihitung dengan membandingkan laju dosis radiasi sebelum melewati penahan radiasi dengan laju dosis setelah melewati penahan radiasi yang ditunjukkan pada Persamaan 4.

$$
\text { Efektifitas }=\frac{D o-D}{D o} \times 100 \%
$$

HVT merupakan ketebalan bahan radiasi yang mampu untuk menyerap intensitas radiasi menjadi setengah dari intensitas mula-mula (Sianturi et al., 2018). Sifat radiasi akan semakin kecil apabila melalui suatu medium dengan nomor atom yang tinggi dan ketebalan medium yang semakin tebal.
Pembangunan tata ruang dengan radiasi pengion harus mempunyai ketebalan dinding yang sesuai dengan syarat yang ditentukan oleh Badan Pengawas Tenaga Nuklir (BAPETEN) dan dilapisi bahan yang mempunyai nomor atom tinggi agar radiasi hambur dapat terserap dengan sempurna (Akadi, 2000). Menurut Peraturan Kepala BAPETEN Nomor 15 Tahun 2014, ruangan yang menggunakan sinar$X$ harus didesain sedemikian rupa agar dosis yang diterima tidak lebih dari setengah NBD dari pekerja radiasi dan masyarakat (BAPETEN, 2014).

Program proteksi radiasi dilakukan untuk melindugi petugas, masyarakat umum, maupun pasien sehingga radiasi dapat dianggap aman digunakan. Ruangan sumber radiasi dibuat dengan dinding penahan radiasi yang terbuat dari $\mathrm{Pb}$ (Plumbum) dan beton karena bahan ini dapat melemahkan intesitas radiasi (Hart \& Dugdale, 2013). Ruang pemeriksaan yang aman memiliki dinding yang terbuat dari bata merah dengan ketebalan $25 \mathrm{~cm}$ dan kerapatan jenis 2,2 $\mathrm{gr} / \mathrm{cm}^{3}$. Ketebalan beton yang digunakan adalah $20 \mathrm{~cm}$ atau setara $2 \mathrm{~mm}$ timbal $(\mathrm{Pb})$. Pintu dan ventilasi ruang pemeriksaan sinar- $X$ dilapisi dengan timbal $(\mathrm{Pb})$ setebal $2 \mathrm{~mm}$, dengan tiap sambungan $\mathrm{Pb}$ dibuat tumpang tindih/overlapping sehingga tingkat radiasi di sekitar ruang pemeriksaan sinar-X tidak melebihi Nilai Batas Dosis (NBD) 1 
mSv/tahun (BAPETEN, 2014). Standar ruang pemeriksaan panoramik memiliki panjang $3 \mathrm{~m}$, lebar $2 \mathrm{~m}$, dan tinggi 2,8 m (Menteri Kesehatan Republik Indonesia, 2008).

Berdasarkan observasi yang telah dilakukan, ruangan panoramik di Instalasi Radiologi RSUD Prof. Dr. MA. Hanafiah SM Batusangkar saat ini belum memiliki ruangan khusus. Ruangan panoramik bersebelahan dengan ruang sinar- $X$ konvensional tanpa disertai pintu. Kaca pembatas antara ruang panel kontrol dengan ruang pesawat panoramik terdapat celah, sehingga memungkinkan radiasi sampai ke ruang panel kontrol.

Penelitian ini dilakukan untuk menguji efektifitas ruangan panoramik dan keamanan ruangan terhadap paparan radiasi sinar- $X$. Pengambilan data dilakukan dengan menggunakan salah satu alat ukur radiasi, yaitu TLD. Salah satu keunggulan alat ukur radiasi ini mampu menyerap dosis radiasi paparan rendah dari 0,1 mGy sampai 1.000 Gy sehingga dapat mengetahui paparan radiasi di suatu medan walaupun dosis paparan tersebut rendah. Alat ukur radiasi lain yang dapat digunakan adalah Surveymeter Unfors-Xi yang mampu mendeteksi dosis radiasi yang sangat rendah, bahkan dalam skala nanoGray (Nicholas Tsoulfanidis, 2011).

Penelitian tentang pengukuran dosis radiasi di Ruangan Radiologi II Rumah Sakit Gigi dan Mulut
(RSGM) Baiturrahmah Padang telah dilakukan oleh Martem et al. (2015) menggunakan Surveymeter Unfors$X i$. Hasil penelitian menunjukkan interval dosis radiasi pada penyinaran panoramik sebesar 0,37 55,69 nGy dan pada penyinaran intraoral sebesar 0,074 - 43,76 nGy. Perisai radiasi Ruangan Radiologi II termasuk perisai yang baik, mampu mengurangi radiasi sebesar 99,33\% saat penyinaran panoramik dan $99,83 \%$ saat penyinaran intraoral (Martem et al., 2015).

Penelitian yang berhubungan dengan pengukuran dosis radiasi telah dilakukan juga oleh Rudi (2013) menggunakan surveymeter digital. Pengukuran dilakukan pada tabung sumber sinar- $X$ dan di sekitar ruang pesawat radiodiagnostik RS dr Kariadi Semarang. Hasil dari penelitian menunjukkan bahwa paparan tertinggi berada di atas tabung sebesar $0,153 \mathrm{mR} / \mathrm{jam}$, sedangkan paparan tertinggi di lingkungan ruang pesawat sinar- $X$ berada di ruang operator CR (Computed Radiography) sebesar 0,031 $\mathrm{mR} / \mathrm{jam}$. Hasil penelitian tersebut menunjukkan bahwa tabung dan lingkungan pesawat sinar- $X$ layak dipakai dan aman ditempati (Rudi, 2013).

Penelitian lain yang berhubungan dengan efektivitas telah dilakukan oleh Kupang (2013), dengan mengukur paparan radiasi menggunakan surveymeter untuk radiasi sebelum dan setelah menembus kaca Timbal $(\mathrm{Pb})$ pada 
enam titik pengukuran. Hasil dari penelitian tersebut menunjukkan bahwa penggunaan kaca $\mathrm{Pb}$ dapat menurunkan laju paparan hingga 99,51\% (Kupang, 2013).

\section{METODE}

Penelitian ini menggunakan metode kuantitatif melalui observasi lapangan, pengambilan data, dan studi kepustakaan. Penelitian dilakukan di ruang panoramik Instalasi Radiologi RSUD Prof. Dr. MA Hanafiah SM Batusangkar.

Menurut observasi yang telah dilakukan di Instalasi Radiologi RSUD Prof. Dr.MA Hanafiah SM Batusangkar, jumlah populasi pasien pemeriksaan Panoramik selama 6 bulan adalah sebanyak 81 orang, dalam sebulan diambil sampel sebanyak 15 orang. Penelitian dilakukan selama satu hari dengan melakukan 15 kali penyinaran dari hasil kalkulasi pasien selama satu bulan.

Pengambilan data dilakukan dengan meletakan 12 buah TLD yang ditempelkan pada empat sisi dinding kaca dan pintu bagian luar ruangan panoramik. TLD kemudian dibawa ke BATAN (Badan Tenaga Nuklir Nasional) untuk mendapatkan hasil bacaan. Dosis yang diperoleh sudah dikurangi dengan radiasi background. Data hasil penelitian kemudian dibandingkan dengan NBD pekerja dan masyarakat umum.

\section{HASIL DAN PEMBAHASAN}

Berdasarkan penelitian yang telah dilakukan, diperoleh hasil pengukuran pembacaan TLD setiap dinding pada ruangan panoramik di Instalasi Radiolgi RSUD Prof. Dr. MA Hanafiah SM Batusangkar yang ditunjukkan pada Tabel 1.

Tabel 1. Hasil Pengukuran Pembaacaan TLD

\begin{tabular}{cccccc}
\hline $\begin{array}{c}\text { Titik } \\
\text { Pengukuran }\end{array}$ & No. TLD & Posisi & $\begin{array}{c}\text { Do } \\
(m G y)\end{array}$ & $\begin{array}{c}\text { D } \\
(m G y)\end{array}$ & $\begin{array}{c}\text { Dosis serap } \\
(\text { Do - D) }\end{array}$ \\
\hline 1 & $25-26$ & Dalam - Luar & 0,096 & 0,096 & 0 \\
2 & $24-23$ & Dalam - Luar & 0,072 & 0,040 & 0,32 \\
3 & $22-21$ & Dalam - Luar & 0,100 & 0,021 & 0,079 \\
4 & $27-28$ & Dalam - Luar & 0,079 & 0,073 & 0,006 \\
5 & $19-20$ & Dalam - Luar & 0,117 & 0,026 & 0,091 \\
6 & $30-29$ & Dalam - Luar & 0,968 & 0,099 & 0,869 \\
\hline
\end{tabular}


Menurut Akadi (2000), laju dosis radiasi elektromagnetik berbanding lurus dengan intensitas radiasi sehingga nilai efektifitas dinding ruangan pemeriksaan. Hasil analisis efektifitas pada setiap titik pengukuran ditunjukkan pada Tabel 2.

Pada dinding 1 dengan TLD no 25 dan 26 diperoleh efektifitas dinding $0 \%$. Hal tersebut berarti dinding pada sisi 1 tidak efektif sebagai penahan radiasi karena hanya mampu menyerap radiasi kurang dari $90 \%$ yang disebabkan karena jarak antara tabung dengan dinding tempat pemasangan TLD adalah $17 \mathrm{~cm}$. Pada dinding sisi 2 dengan TLD no 23 dan 24 diperoleh efektifitas dinding $44,44 \%$, sedangkan pada dinding sisi 3 dengan TLD no 21 dan 22 diperoleh efektifitas dinding 79\% sehingga dapat dikatakan dinding-dinding pada sisi 2 dan 3 tidak efektif sebagai penahan radiasi (Mulyati et al., 2018).

Pada dinding sisi 4 dengan TLD no 27 dan 28 diperoleh efektifitas dinding 7,59\%; yang berarti pada dinding sisi 4 tidak aman sebagai penahan radiasi. Hal ini disebabkan oleh tinggi dinding tidak sampai ke langit-langit, sedangkan menurut MENKES RI No. 366 tahun 1997 tinggi dinding yang aman ialah 2,8 m (Rochmayanti et al., 2019).

Pada dinding kaca sisi 5 diperoleh efektifitas $77,77 \%$ dengan ketebalan $1 \mathrm{~cm}$ kaca $\mathrm{Pb}$ dan pada pintu sisi 6 diperoleh efektifitas $86,9 \%$. Berdasarkan hasil tersebut, dapat disimpulkan dinding-dinding panoramic di tempat uji tidak efektif sebagai penahan radiasi karena menurut konsep TVT, dinding yang baik bisa menahan radiasi minimal $90 \%$.

Tabel 2. Hasil Analisis Efektifitas Setiap Titik Pengukuran

\begin{tabular}{ccc}
\hline $\begin{array}{c}\text { Titik } \\
\text { Pengukuran }\end{array}$ & $\begin{array}{c}\text { Dosis } \\
\text { serap } \\
\text { (Do - D) }\end{array}$ & $\begin{array}{c}\text { Efektifitas } \\
(\%)\end{array}$ \\
\hline 1 & 0 & 0 \\
2 & 0,32 & 44,44 \\
3 & 0,079 & 79 \\
4 & 0,006 & 7,59 \\
5 & 0,091 & 77,77 \\
6 & 0,869 & 86,9 \\
\hline
\end{tabular}

\section{Radiasi Hambur di Sekitar Ruang Pemeriksaan Panoramik}

Setelah dilakukan pengukuran di ruangan sekitar ruang pemeriksaan panoramik, diperoleh nilai dosis ekivalen yang ditunjukkan pada Tabel 3. Menurut hasil bacaan TLD dari BATAN, radiasi hambur yang terdapat di sekeliling ruangan panoramik RSUD Prof. Dr. MA Hanafiah SM Batusangkar yaitu: $0,0032 \mathrm{mSv}$ untuk sisi dinding 1, 0,0013 untuk sisi dinding 2, disebabkan oleh arah sumber radiasi yang sangat dekat dengan dinding. Radiasi hambur pada dinding sisi 3 adalah $0,0007 \mathrm{mSv}$ yang disebabkan oleh arah sinar matahari yang mengarah langsung ke dinding tersebut (Benchimol et al., 2018).

Pada dinding sisi 4, radiasi hamburnya adalah $0,0024 \mathrm{mSv}$ yang 
disebabkan oleh tinggi dindingnya yang tidak sampai ke langit-langit, sedangkan menurut (Menteri Kesehatan Republik Indonesia, 2008) tinggi dinding yang aman ialah 2,8 m. Radiasi hambur dinding sisi 5 sebanyak 0,0008 mSv karena adanya celah antara dinding dan kaca pada ruangan panel kontrol dan pada dinding sisi 6 radiasi hamburnya adalah $0,0033 \mathrm{mSv}$ (Hart \& Dugdale, 2013).

Tabel 3. Hasil Perhitungan Dosis Ekivalen

\begin{tabular}{cccc}
\hline $\begin{array}{c}\text { No } \\
\text { TLD }\end{array}$ & $\begin{array}{c}\text { Dosis } \\
\text { serap } \\
(\mathrm{mGy})\end{array}$ & $\begin{array}{c}\text { Dosis } \\
\text { ekivalen } \\
(\mathrm{mSv}) / \\
30 \text { hari }\end{array}$ & $\begin{array}{c}\text { Dosis/ } \\
\text { hari } \\
(\mathrm{mSv})\end{array}$ \\
\hline 26 & 0,096 & 0,096 & 0,0032 \\
23 & 0,040 & 0,040 & 0,0013 \\
21 & 0,021 & 0,021 & 0,0007 \\
28 & 0,073 & 0,073 & 0,0024 \\
20 & 0,026 & 0,026 & 0,0008 \\
29 & 0,099 & 0,099 & 0,0033 \\
\hline
\end{tabular}

Tabel 4. Akumulasi Dosis yang Diterima Pekerja Selama Satu Tahun

\begin{tabular}{|c|c|c|c|}
\hline $\begin{array}{l}\text { No } \\
\text { TLD }\end{array}$ & $\begin{array}{l}\text { Dosis } \\
\text { serap } \\
(\mathrm{mGy})\end{array}$ & $\begin{array}{c}\mathrm{D}(\mathrm{mSv}) / \\
\text { minggu }\end{array}$ & $\begin{array}{c}\mathrm{D} \\
(\mathrm{mSv}) \\
/ \\
\text { tahun }\end{array}$ \\
\hline 26 & 0,096 & 0,0224 & 0,2688 \\
\hline 20 & 0,026 & 0,056 & 2,912 \\
\hline 29 & 0,099 & 0,0231 & 1,2012 \\
\hline
\end{tabular}

Akumulasi nilai batas dosis untuk pekerja radiasi di Instalasi Radiologi RSUD Prof. Dr. MA Hanafiah SM Batusangkar dapat dilihat pada Tabel 4. Akumulasi dosis dari keseluruhan dinding masih aman untuk pekerja radiasi karena kurang dari $20 \mathrm{mSv}$ dalam 1 tahun.

Tabel 5. Akumulasi dosis yang diterima masyarakat umum

\begin{tabular}{ccc}
\hline $\begin{array}{c}\text { No } \\
\text { TLD }\end{array}$ & $\begin{array}{c}\text { Dosis serap } \\
(\mathrm{mGy})\end{array}$ & $\begin{array}{c}\mathrm{D}(\mathrm{mSv}) \\
/ \text { Tahun }\end{array}$ \\
\hline 23 & 0,040 & 0,48 \\
21 & 0,021 & 0,252 \\
\hline
\end{tabular}

Akumulasi dosis yang diterima masyarakat umum ditunjukkan pada Tabel 5. Akumulasi dari nilai batas dosis masyarakat masih aman karena kurang dari $1 \mathrm{mSv}$ dalam satu tahun (IAEA, 2015).

\section{KESIMPULAN}

Berdasarkan hasil penelitian dapat disimpulkan dinding ruangan panoramik di RSUD Prof. Dr. MA Hanafiah SM Batusangkar hanya dapat menahan radiasi kurang dari $90 \%$ dan dinding tersebut dikategorikan kurang efektif dalam menahan radiasi. Pihak rumah sakit harus merenovasi kembali dinding ruangan panoramik agar sesuai dengan standar yang telah ditetapkan agar radiasi tidak menembus dinding panoramik yang dapat membahayakan petugas dan masyarakat umum di sekitar ruangan.

\section{DAFTAR PUSTAKA}

Akadi, M. 2000. Dasar Dasar Proteksi Radiasi. Bandung: PT RINEKA CIPTA.

Ancila, C., \& Hidayanto, E. 2016. 
Radiologi Dental Panoramik. Youngster Physics Journal, 5(4), 441-450.

Bapeten. 2011. Perka Bapeten Nomor 8

Tahun 2011 tentang Keselamatan

Radiasi dalam Penggunaan

Pesawat Sinar-X Radiologi

Diagnostik dan Intervensional.

BAPETEN. 2014. Peraturan Kepala

Badan Pengawas Tenaga Nuklir

Nomor 15 Tahun 2014 tentang

Keselamatan Radiasi dalam

Produksi Pesawat Sinar-X

Radiologi Diagnostik Dan Intervensional.

Benchimol, D., Koivisto, J., Kadesjö, N., \& Shi, X. Q. 2018. Effective dose reduction using collimation function in digital panoramic radiography and possible clinical implications in dentistry. Dentomaxillofacial Radiology, 47(7). https://doi.org/10.1259/dmfr .20180007

Dianasari, T. 2016. Gambaran Penerapan Manajemen Keselamatan Radiasi dalam Penggunaan Pesawat Sinar X di Instalasi Radiologi RSUD Ungaran Kabupaten Semarang Tahun 2016: 1-122.

Hart, G., \& Dugdale, M. 2013. Radiation Protection in Dental X-Ray Surgeries-Still Rooms for Improvement. British Dental Journal, 214(6): 1-5. https://doi.org/10.1038/sj.bdj .2013.274
Hiswara, E. 2015. Buku Pintar Proteksi dan Keselamatan Radiasi di Rumah Sakit.

IAEA. 2015. World Wide Implementation of Digital Imaging in Radiology. Iaea Human Health Series, 28: 1-216. http://www.iaea.org/Publicat ions/index.html

Kupang, P. W. Z. J. 2013. Pengukuran Laju Paparan Radiasi Sinar-X pada Ruang Operator RSUD. Prof. DR. W. Z. Johannes Kupang. Youngster Physics Journal, 2(2): 49-52.

Martem, D. R., Milvita, D., Yuliati, H., \& Kusumawati, D. D. (2015). Pengukuran Dosis Radiasi Ruangan Radiologi di Rumah Sakit Gigi dan Mulut (RSGM) Baiturrahmah Padang Menggunakan Surveymeter Unfors-Xi. Jurnal Fisika Unand, 4(4): 414-418.

Menteri Kesehatan Republik Indonesia. 2008. Standar Pelayanan Radiologi Diagnostik Di Sarana Pelayanan Kesehatan (p. NOMOR 1014/MENKES/SK/X/2008).

Mulyati, S., Daryati, S., \& Wibowo, A. S. 2018. Efektifitas Diversifikasi Bahan Dinding Perisai Radiasi Menggunakan Beton Ringan (Hebel) yang Dilapisi Timah Hitam $(\mathrm{Pb})$.

Nicholas Tsoulfanidis. 2011. Measurement and Detection of Radiation. Hemisphere 
Publishing Corparation.

Rochmayanti, D., Daryati, S., \& Kartikasari, Y. 2019. Radiation Exposure Profile in Radiological Department to Supporting Protection Programs in Hospital. Jurnal Imejing Diagnostik, 5(1): 20-24.

Rudi, S. 2013. Pengukuran Paparan Radiasi Pesawat Sinar - X Di Instalasi Radiodiagnostik Untuk Proteksi Radiasi.Unnes Physics Journal, 1(1).

Sianturi, H. A., Rianna, M., Sembiring, T., \& Situmorang, M. 2018. Pengukuran dan Analisis Dosis Radiasi Keluaran pada Pesawat Sinar-X yang Berusia Lebih dari 10 Tahun pada Rumah Sakit di Kota Medan. Journal Of Aceh Physic Society, 7(1): 1-5. http://www.jurnal.unsyiah.ac .id/JAcPS

Street, H. C. 1994. The British Journal of Radiology Review Article: Radiation Protection in Dental Radiology. 67(803): 1041-1049.

Trikasjono, T., Hanifasari, K., \& Suhendro, B. 2015. Analisis Paparan Radiasi Lingkungan Ruang Radiologi di Rumah Sakit dengan Program Delphi. Jurnal Teknologi Elektro, 6(3). https://doi.org/10.22441/jte.v $6 \mathrm{i} 3.803$

White, S. C., \& Mallya, S. M. 2012. Update on The Biological Effects of Ionizing Radiation, Relative Dose Factors and Radiation Hygiene. Australian Dental Journal, 57: 2-8. https://doi.org/10.1111/j.183 4-7819.2011.01665.x 